\title{
Familial pericentric inversion (10) and its effect on two offspring
}

MARIA TERESA RODRIGUEZ, MARIA JOSÉ MARTIN, AND JOSÉ ANTONIO ABRISQUETA

Instituto de Genética, CSIC, Madrid, Spain.

SUMMARY A pericentric inversion (10)(p15q24) was observed in three generations of a family. One daughter of the inversion carrier was found to have the inv(10) and trisomy 18 . The other offspring had a recombinant (10) chromosome.

Received for publication 3 January 1984. Accepted for publication 15 January 1984.

\section{Case report}

A pericentric inv(10)(p15q24) was observed in three generations of a family. The family came to our attention when the proband (III.5, fig 1) was born, showing clinical features of Edwards' syndrome. She was born at 40 weeks' gestation after a normal pregnancy. Birth weight was $1780 \mathrm{~g}$. She died at 10

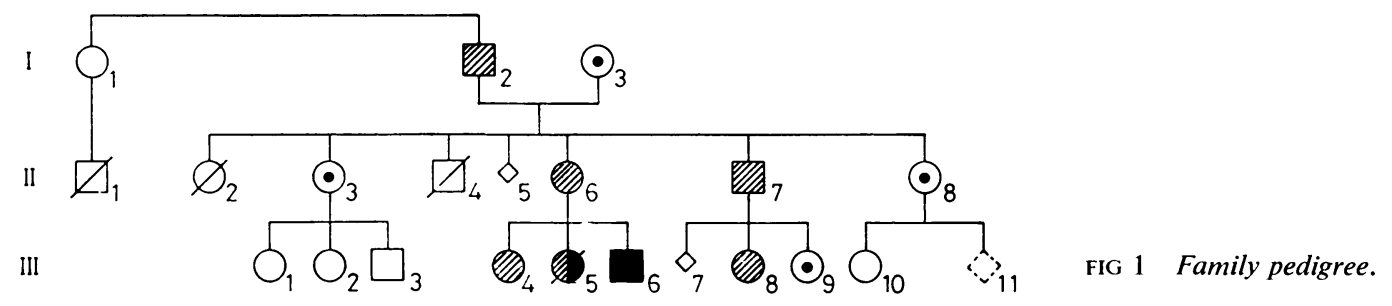

\footnotetext{
- Normal

Q1]

Inveizion 10

Partial trisuny 10qter

E inversion 10 and trisomy 18

Not examined
}

FIG 2 GTG banded metaphase from the proband (III.5) showing the inverted and normal chromosomes 10 (long arrows) and the trisomy 18 (short arrows). 
days She was the second child of unrelated parents: the mother was 35 and the father 48 years old.

Another malformed child was born to the same couple one year later. This second child (III.6) was a boy also born at term after an uneventful pregnancy.

The amniotic fluid was meconium stained. Apgar score was 9 at 1 minute. At birth he weighed $2000 \mathrm{~g}$, length was $51 \mathrm{~cm}$, and head circumference $26 \mathrm{~cm}$. Dysmorphic features included dolichocephaly, high and large forehead, arched eyebrows, microphthalmia, hypertelorism (interpupillary distance $3 \cdot 5$ $\mathrm{cm})$, epicanthus, antimongoloid slants, narrow palpebral fissures, flat and broad nose bridge, high arched palate, prominent upper lip, microretrognathia, low set ears, long thin fingers, ulnar hand deviation. clinodactyly, and a gap between the first and second toes. Examination of the chest and heart was normal. At 2.13 months of age, he weighed $4180 \mathrm{~g}$ and his head circumference was $39 \cdot 5 \mathrm{~cm}$.

\section{('YTOGENETIC' STUDIES}

Chromosome analyses of cultured lymphocytes by $\mathrm{Q}, \mathrm{G}$, and T banding were performed. The proband's karyotype was 47,XX,inv(10)(p15q24), 18 (fig 2). The inv(10) was also present in her mother. The father's chromosomes were normal. The same inversion was found in four other members of the family (I.2, II.7, III.4, and III.8).

The second child (III.6) carried a recombinant abnormal chromosome 10: 46, XY, rec(10)dup q, inv(10)(p15q24)mat (fig 3). Therefore the boy had a duplication of $10 \mathrm{q} 24$-qter and a deletion of distal p15.

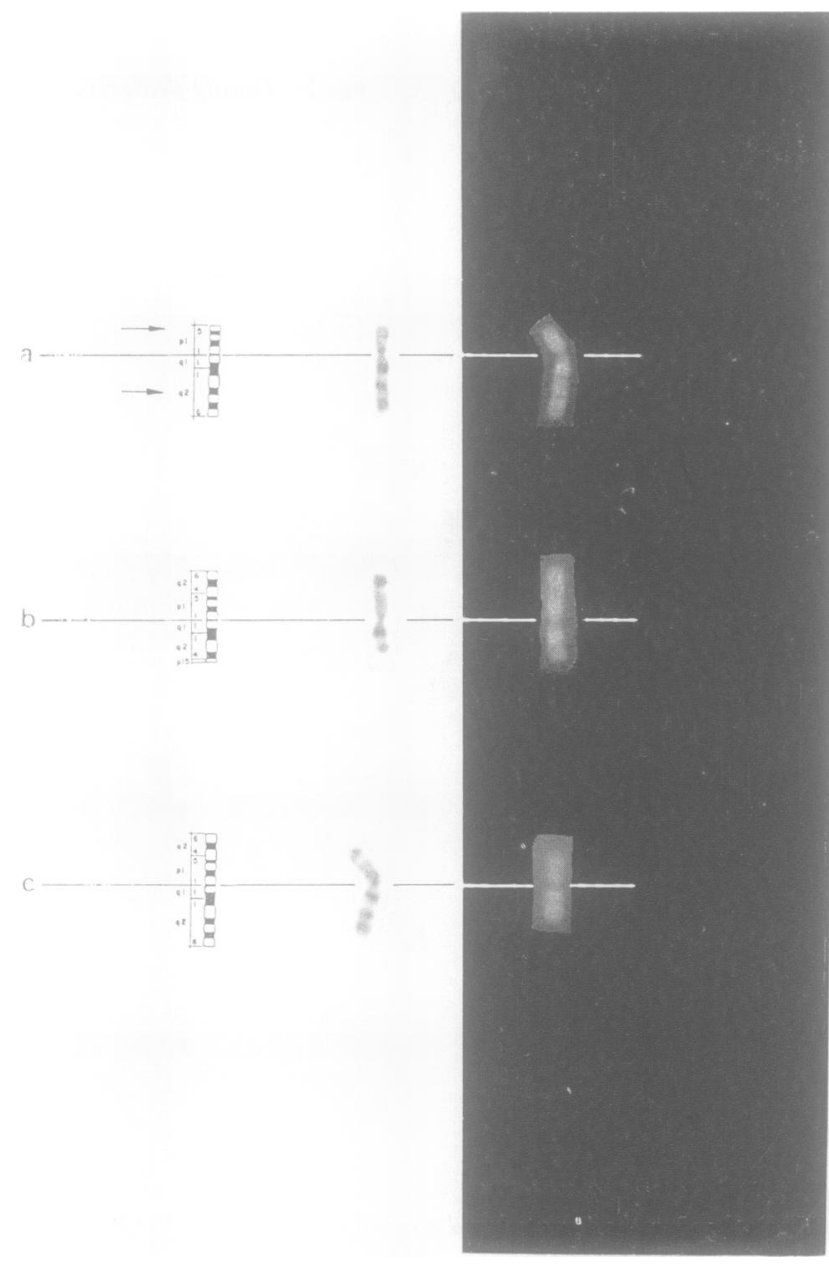

FIG $3 G T G$ and $Q F Q$ handing of (a) normal chromosome 10, (b) inv(10)(p15q24), and (c) recombinant (10), dup q,inv $(10)(p / 5 q 24)$. 


\section{Discussion}

Segregation analysis of the inversion through three generations showed a carrier to non-carrier ratio of $4: 3$.

As a direct result of the meiotic behaviour of the inversion, a recombinant chromosome 10 , similar to that described by Dutrillaux et al, ${ }^{1}$ was found in III.6, who showed the clinical features of the partial trisomy $10 \mathrm{q}$ syndrome. ${ }^{2}$

In addition to the risk related to the segregation of the inverted chromosome itself, an interchromosomal effect may also exist which could influence non-disjunction involving another chromosomal pair.

The existence of this chromosomal interference in animals has been demonstrated, particularly in Drosophila. ${ }^{3}$ In man, this effect has been observed mainly in balanced translocations ${ }^{4}$ and in only a few instances of pericentric inversions (excluding those affecting chromosome 9 ). ${ }^{5-9}$

In the present family, the occurrence of trisomy 18 in the offspring of an inversion carrier adds to the evidence supporting this type of chromosomal effect. However, the age of the parents (35 and 48) may also have contributed to the aneuploidy.

Nevertheless with regard to genetic counselling, in addition to the risk directly attributed to the balanced rearrangement, the influence of an interchromosomal effect should also be considered.

We thank Teresa Zorita, Antonio del Mazo, Amparo Cerrajero, and Victoria Lafita for technical assistance, and the FNAS (Ministerio de Sanidad y Seguridad Social) for their support.

\section{References}

1 Dutrillaux B, Laurent C, Roberts JM, Lejeune J. Inversion pericentrique, inv(10), chez la mère et anéusomie de recombinaison, inv(10)rec(10), chez son fils. Cytogenet Cell Genet $1973 ; 12: 245-53$.

2 de Grouchy J, Turleau C. Atlas des maladies chromosomiques. 2nd ed. Paris: Expansion Scientifique Française, 1982:178-95.

${ }^{3}$ Schultz J, Redfield H. Interchromosomal effect on crossing-over in Drosophila. Cold Spring Harbor $S_{1}: m$ posium on Quantitative Biology 1951;16:175.

4 Wolstenholme J, Faed MJW, Robertson J, Lamont MA. Chromosome abnormality in couples with histories of multiple abortions. The outcome of pregnancies subsequent to ascertainment and a study of familial translocation carriers. Hum Genet 1983 ;63:45-7.

5 Wikramanayake E, Renwick JH, Ferguson-Smith MA. Chromosomal heteromorphisms in the assignment of loci to particular autosomes: a study of four pedigrees. Ann Genet (Paris) 1971 ; 14:245-56.

6 Catti A. Inversions familiales et autres aberrations chromosomiques concomitantes. J Genet Hum 1975; suppl 23:92-5.

7 Hamerton JL, Canning N, Ray M, Smith S. A cytogenetic survey of 14,069 newborn infants. I. Incidence of chromosome anomalies. Clin Genet 1975;8:223-43.

8 Leonard C, Hazael-Massieux P, Boequet L, LargetPiet L, Boué J. Inversion pericentrique inv(2)(p11q13) dans des familles non apparentées. Humangenetik 1975; 28:121-8.

9 Yunis E, Torres de Caballero O. Duplication deficiency as the result of meiotic segregation of a maternal inv(10). Hum Genet 1981;57:71-4.

Correspondence and requests for reprints to $\mathrm{Dr}$ M T Rodriguez, Instituto de Genética, Valázquez 144, Madrid 6, Spain. 